\title{
Serum D-glutamyl transferase following myocardial infarction
}

\author{
MARGARET D. CONNELL \\ From the Department of Biochemistry, Western Infirmary, Glasgow
}

SYNOPSIS D-glutamyl transferase (GMT) activity was measured in 49 patients with proven myo- $\frac{\sigma}{8}$ cardial infarction. Twenty-three patients had normal GMT activity and 26 had increased GMT? activity. Most of the patients with increased GMT had evidence of liver dysfunction and it is sug- $\sigma$ gested that any increases in serum GMT activity following myocardial infarction are a result of ${ }^{\circ}$ secondary liver damage rather than a release of GMT from cardiac tissue.

D-glutamyl transferase ${ }^{1}$ (GMT) (EC 2.3.2.1) has been found in hepatic, renal, pancreatic, and pulmonary tissues (Szczeklik, Orłowski, and Szewczuk, 1961) and has been demonstrated along the hepatobiliary tract, in pancreatic acini and small ductules, and in the luminal border of epithelial cells (Naftalin, Child, Morley, and Smith, 1969). Naftalin et al (1969), however, could not demonstrate GMT activity in human cardiac tissue and postulated that any increases in serum GMT activity after myocardial infarction were due to secondary liver damage. In serum GMT has been shown to be increased in hepatobiliary disorders (Szczeklik et al, 1961). However, several workers (Agostini, Ideo, and Stabilini, 1965; Ravens, Gudbjarnson, Cowan, and Bing, 1969; Szczeklik, Szewczuk, Howosad, and Kołaczkowska, 1972) have reported that serum GMT activity is increased after myocardial infarction with peak activities varying from the fourth to fourteenth day after infarction.

Lactate dehydrogenase (LD) (EC 1.1.1.27) activity in serum is increased after myocardial infarction and in hepatocellular damage; isoenzyme separation enables increases in serum LD from cardiac damage and liver damage to be distinguished (Latner and Skillen, 1968).

This work was designed to investigate serum GMT activity in patients who have had a myocardial infarction and to relate this to the LD isoenzyme pattern with particular reference to increases in $\mathrm{LD}_{5}$, the liver isoenzyme, and to

\footnotetext{
${ }^{1}$ Also known as $\gamma$-glutamyl transpeptidase.

Received for publication 29 June 1973.
}

determine the probable source of increased GMT activity in serum following myocardial infarction.

\section{Materials and Methods}

Fifty-three patients (11 females and 42 males). with a provisional diagnosis of myocardial infarctiळi and increased serum aspartate transaminase (AS (EC 2.6.1.1.) activity were studied at intervals for up to four weeks after hospital admission or until death ( 11 cases). In all patients at least three speci- $\stackrel{\varnothing}{\varrho}$ mens were obtained covering a time span of at $\overrightarrow{\overrightarrow{0}}$ least 10 days.

Aspartate transaminase and alanine transaminase (ALT) (EC 2.6.1.2.) (Fingerhut, Ferzola, Marsh, and Levine, 1962) and total LD (Varley, 1967) were measured, and LD isoenzymes separated on cel-o lulose acetate membrane (Preston, Batsakis, and $\frac{5}{3}$ Briere, 1965) on fresh specimens or specimens stored at 4 . The LD isoenzyme patterns were $\frac{0}{3}$ assessed qualitatively against a normal serum on each test run.

D-glutamyl transferase activity was measured $\frac{D}{0}$ using a commercial $\mathrm{kit}^{2}$ which employs the method of Szasz (1969). For quality control purposes $N$ aliquots of a deep frozen pool of serum were $\mathrm{N}$ thawed and assayed with each batch; the mean activity was $121 \mathrm{U} / 1$ (coefficient of variation $5 \cdot 1 \%$ ). $\mathrm{\omega}$ In a series of 50 sera, from staff and outpatients in whom neither hepatobiliary nor cardiac disease was suspected ( 25 males, 25 females) age range 16-71, assayed for GMT, the mean activity was? $15 \mathrm{U} / \mathrm{l}$ (standard deviation $8 \mathrm{U} / \mathrm{l}$ ) for males and 10

\footnotetext{
${ }^{2}$ Boehringer Corporation C-system (catalogue no. 15794 TMBG).
} 
$\mathrm{U} / \mathrm{l}$ (standard deviation $7 \mathrm{U} / \mathrm{l}$ ) for females. For the purpose of this study, sera with GMT activity greater than $30 \mathrm{U} / 1$ were considered abnormal.

In this laboratory, normal ranges for the other enzymes measured are AST 5-40 Reitman Frankel (RF) units $/ \mathrm{ml}$, ALT 5-35 RF units $/ \mathrm{ml}$, and up to $190 \mathrm{U} / \mathrm{l}$ for lactate dehydrogenase.

\section{Results}

Of the 53 patients studied, 49 were subsequently shown to have had a recent myocardial infarction on clinical, electrocardiographic, and biochemical evidence. Of the remaining patients, two had severe left ventricular failure and palpable liver and two patients had cholecystitis; all four patients had markedly increased serum AST, ALT, and GMT activities, normal $L D_{1}$ and $L_{2}$, and increased $L_{5}$. These four patients are not considered further in the study.

\begin{tabular}{lcc}
\hline & \multicolumn{2}{l}{$G T P$} \\
\cline { 2 - 3 } & Raised & Normal \\
\hline No. of patients & 26 & 23 \\
LD $_{1}$, LD $_{2}$ only increased & 4 & 18 \\
LD & LD, LD & increased \\
ALT normal & 22 & 5 \\
ALT raised & 4 & 13 \\
\hline
\end{tabular}

Table Serum GMT, ALT, and LD isoenzyme activities in 49 patients with myocardial infarction

Of the 49 patients 26 had increased GMT activity on one or more occasion and 22 of these had increased $L_{5}$ isoenzyme present in addition to $L D_{1}$ and $L D_{2}$ (see table). In two of the four patients where no increase in $\mathrm{LD}_{5}$ was noted, GMT activity was only slightly increased, 32,46 , and 55 $\mathrm{U} / 1$ and 32,34 , and $45 \mathrm{U} / 1$; no other evidence of liver dysfunction was noted and ALT was normal. In the third patient markedly increased activity of GMT (162 U/l) was noted seven days after infarction, though originally only a slight increase (36 U/l) was observed; an episode of congestive cardiac failure was recorded on the sixth day after infarction and ALT was higher than AST till the sixteenth day after infarction. The fourth patient had increased GMT (125 U/l) within two days of infarction and GMT was still slightly increased three weeks later; this patient had a history of three previous myocardial infarctions and episodes of left ventricular failure and congestive cardiac failure were recorded on this admission; ALT was increased in the initial period to 90,108 , and $60 \mathrm{RF}$ units $/ \mathrm{ml}$ when AST was $262,387,145 \mathrm{RF}$ units $/ \mathrm{ml}$.
There were 23 patients with normal GMT activities throughout the period of study. Five of these patients had slight increases in $\mathrm{LD}_{5}$ in addition to $L D_{1}$ and $L D_{2}$. In three of the five ALT was always less than $60 \mathrm{RF}$ units $/ \mathrm{ml}$; there was no other record of liver dysfunction. In the other two patients, one had ALT continuously rising and greater than AST, and congestive cardiac failure was demonstrated at necropsy; the other also had congestive cardiac failure demonstrated at necropsy and ALT less than $100 \mathrm{RF}$ units $/ \mathrm{ml}$.

The table also shows that most of the patients with only $L_{1}$ and $L_{2}$ increased had normal GMT activities throughout the period of study; the four exceptions (where serum GMT was increased and only $L D_{1}$ and $L D_{2}$ present) have been described above. The table also shows that while most of the patients with $L D_{5}$ increased in addition to $L D_{1}$ and $\mathrm{LD}_{2}$ have increased GMT there are five patients where GMT is normal throughout the period of study. These patients also are described above.

In the patients where serum GMT activity was increased after myocardial infarction no consistent or definite pattern of increase of GMT was observed. In patients with normal GMT, ALT was increased in less than half of the patients and was greater than $100 \mathrm{RF}$ units/ml in only one patient. Where GMT was abnormal, ALT activity was nearly always increased.

\section{Discussion}

Increases in serum GMT have been reported in a wide variety of liver disorders (Szczeklik et al, 1961; Jacobs, 1972). Although increases in GMT following myocardial infarction have been reported (Agostini et al, 1965; Ravens et al, 1969; Szczeklik et al, 1972), little evidence has been found that increased serum GMT activity is derived from damaged human cardiac tissue. Ravens et al (1969) in work on dogs showed an increase in free and particle-bound GMT following experimentally induced myocardial infarction and suggested that this reflected a 'reactive reparative process taking place in infarcted tissue'. Naftalin et al (1969) suggested that increases in serum GMT activity following myocardial infarction were due to secondary liver damage.

Results in this study show that increased serum GMT activity mainly occurs when there is secondary damage to the liver as shown by increases in $\mathbf{L D}_{5}$. Alanine transaminase is a useful index of liver damage (Goldberg, 1971) but as ALT is also found in cardiac tissue (Schmidt and Schmidt, 1967), though proportionally much less than is AST, it is unwise to use increases in serum ALT activity alone as an index of liver damage following myo- 
cardial infarction. It has also been shown in this study that ALT, a useful index of liver damage, is more often increased in patients with increased GMT activity and favours the argument that increases in serum GMT activity following myocardial infarction are a result of secondary liver damage.

Rosalki, Tarlow, and Rau (1971) suggested that increases in serum GMT activity in patients receiving phenobarbitone and other anticonvulsants should be interpreted with caution as he showed that patients receiving these drugs for several months had increased serum GMT activity. Microsomal induction of liver GMT by these drugs may occur within a few days but cell injury may be necessary before GMT is released. One patient who had increased serum GMT activity and only $L D_{1}$ and $L D_{2}$ increased had received a number of drugs, including amylobarbitone and phenobarbitone, which may have induced GMT in liver tissue. However, several patients whose serum GMT activity remained normal throughout the period of study had also received these drugs so it is not possible to attribute increased serum GMT activity solely to drug therapy in these patients. Lactate dehydrogenase is not a microsomal enzyme (Schmidt and Schmidt, 1967; Rosalki, 1971) and increases in serum LD activities may be due to a different mechanism from that causing increases in serum GMT activity.

Increases in total serum LD activity in liver diseases are usually less marked than increases in AST and ALT (Wilkinson, 1962), though it has been reported (Latner and Skillen, 1968) that increases in $\mathrm{LD}_{5}$ in serum can be seen in liver disease when total LD activity is normal.

Enzyme induction or the sensitivity of $\mathrm{LD}_{5}$ in detecting liver disease could account for some of the results where GMT or $\mathrm{LD}_{5}$ activity alone is increased.
The results in this study show that increases in serum GMT activity following myocardial infarction 은 occur in $53 \%$ of patients; it appears that the increase $\Rightarrow$ in serum GMT activity is a result of damage to $?$ liver tissue rather than to the release of enzyme from infarcted cardiac tissue.

\section{References}

Agostini, A., Ideo, G., and Stabilini, R. (1965). Serum gamma-glutamyl transpeptidase activity in myocardial infarction. Brit. Heart J., 27, 688-690.

Fingerhut, B., Ferzola, R., Marsh, W. H., and Levine, J. B. (1962) An automated method for a colorimetric determination of serum glutamic oxaloacetic transaminase. Ann. N.Y. Acad. Sci., 102, 137-143.

Goldberg, D. M. (1971). Enzymes in the diagnosis of myocardial: infarction and liver disease. Ann. clin. Biochem., 8, 195-200.

Jacobs, W. L. W. (1972). Gamma-glutamyl transpeptidase in diseases of the liver, cardiovascular system and diabetes mellitus. $\triangle$ Clin. chim. Acta, 38, 419-434.

Latner, A. L., and Skillen, A. W. (1968). Isoenzymes in Biology and Medicine, pp. 146-169. Academic Press, London and New York.-

Naftalin, L., Child, V. F., Morley, D. A., and Smith, D. A. (1969).C Observations on the site of origin of serum gamma-glutamyID transpeptidase. Clin. chim. Acta, 26, 297-300.

Preston, J. A., Briere, R. O., and Batsakis, J. G. (1965). Rapid electrophoretic separation of lactate dehydrogenase isoenzymes $\frac{\nabla}{\sigma}$ on cellulose acetate. Amer. J. clin. Path., 43, 256-260.

Ravens, K. G., Gudbjarnson, S., Cowan, C. M., and Bing, R. J. (1969). Gamma-glutamyl transpeptidase in myocardial infarc- $\overrightarrow{0}$ tion. Circulation, 39, 693-700.

Rosalki, S. B., Tarlow, D., and Rau, D. (1971). Plasma gam glutamyl transpeptidase elevation in patients receiving enzymeinducing drugs. (Letter) Lancet, 2, 376-377.

Schmidt, E., and Schmidt, F. W. (1967). Guide to Practical Enzym Diagnosis, p. 26. Boehringer and Soehne, Mannheim.

Szasz, G. (1969). A kinetic photometric method for serum gammaglutamyl transpeptidase. Clin. Chem., 15, 124-136.

Szczeklik, A., Szewczuk, A., Howsad, H., and Kolaczkowska, B. (1972). Serum peptidases in myocardial infarction. Brit. Heart $J$., 34, 232-237.

Szczeklik, E., Orłowski, M., and Szewczuk, A. (1961). Serum gamma-극 glutamyl transpeptidase activity in liver disease. Gastroenterology, 41, 353-359.

Varley. H. (1967). Practical Clinical Biochemistry, 4th ed., p. 278.ర Heinemann, London.

Wilkinson, J. H. (1962). An Introduction to Diagnostic Enzymology p. 151. Arnold, London. 